\title{
The impact of malnutrition on idiopathic dilated cardiomyopathy in children
}

\author{
Vitor M. P. Azevedo' ${ }^{1}$, Francisco M. Albanesi Filho², Marco A. Santos ${ }^{3}$, \\ Márcia B. Castier ${ }^{4}$, Bernardo R. Tura 5
}

\begin{abstract}
Objective: To analyze the prognostic value of malnutrition in children with idiopathic dilated cardiomyopathy.

Methods: This is a retrospective study of 165 patients with idiopathic dilated cardiomyopathy, diagnosed from September 1979 to March 2003. It analyzed the following variables: gender, age, previous viral illness in the preceding 3 months, functional class according to the New York Heart Association (NYHA), evaluation of nutritional status (normal $v s$ malnutrition), percentile and standard deviation ( $z$ index) of weight. Weight was measured 744 times during the first 72 months, 93 during the first month. Statistical analysis was performed by chi-squared, Student $t$ test and analysis of variance for repeated measures (ANOVA). Ninety-five percent confidence intervals (CI95) and odds ratios (OR) were calculated. An alpha value of 0.05 and beta of 0.80 were used.

Results: Mean age at presentation was $2.2 \pm 3.2$ years with higher incidence in those younger than 2 years ( $75.8 \%$ CI95 $=68.5 \%$ to $82.1 \%)(p<0.0001)$. NYHA classes III and IV were observed in $81.2 \%$ (CI95 $=74.4 \%$ to $86.9 \%$ ) $(p<0.0001)$ and all 40 deaths were this group $(p=0.0008)$. At presentation, myocarditis occurred in $39.4 \%$ $(\mathrm{CI} 95=31.9 \%$ to $47.3 \%)(p=0.0001)$ and a high level of association between myocarditis and previous viral illness was observed $(p=0.0005)(O R=3.15-$ CI95 $=1.55$ to 6.44$)$. Malnutrition at presentation did not influence death $(p=0.10)$, however progressive malnutrition was a marker for death $(p=0.02)(O R=3.21$-CI95 $=1.04$ to 9.95$)$. No significant differences weight percentiles $(p=0.15)$ or in z scores $(p=0.14)$ were observed. Observed mean weight percentiles $(34.9 \pm 32.6$ vs $8.6 \pm 16.0)(p<0.0001)$ and $z$ scores $(-0.62 \pm 1.43 v s-2.02 \pm 1.12)(p<0.0001)$ during the study period were greater among survivors. ANOVA demonstrated significant differences in weight percentile progression $(p=0.0417)$ and $z$ scores $(p=0.0005)$ from the first month onwards.
\end{abstract}

Conclusion: The evaluation of nutritional status. is easy to performer, it does not imply additional costs and should become routine for children with chronic heart failure.

J Pediatr (Rio J). 2004;80(3):211-6: Dilated cardiomyopathy, children, malnutrition, heart failure.

\section{Introduction}

Heart failure (HF) can be defined as a clinical syndrome in which the heart is unable to adequately fulfill its pumping function and cannot supply enough oxygenated blood to

1. MSc. Doctoral student, Universidade do Estado do Rio de Janeiro (UERJ). Instituto Nacional de Cardiologia Laranjeiras, Rio de Janeiro, RJ, Brazil.

2. Professor, Universidade do Estado do Rio de Janeiro (UERJ), Rio de Janeiro, RJ, Brazil.

3. MSc. Instituto Nacional de Cardiologia Laranjeiras, Rio de Janeiro, RJ, Brazil.

4. PhD. Universidade do Estado do Rio de Janeiro (UERJ), Rio de Janeiro, RJ, Brazil.

5. MSc. Instituto Nacional de Cardiologia Laranjeiras, Rio de Janeiro, RJ, Brazil.

Manuscript received Oct 31 2003, accepted for publication Feb 112004. meet demand necessary for normal tissue metabolism, including that necessary for growth and development. ${ }^{1}$

Ventricular dysfunction may be caused by increased preload (severe stenosis of the aorta, coarction of the aorta or chronic systemic arterial hypertension), by increased afterload (mitral insufficiency or left-right shunt as in intraventricular communication) or because of an intrinsic cardiac muscle injury (myocarditis or idiopathic dilated cardiomyopathy). ${ }^{2}$ If we list the primary etiologies of childhood $\mathrm{HF}$, congenital heart disease, rheumatic disease, arrhythmia, myocarditis and idiopathic dilated cardiomyopathy (IDCM) stand out. ${ }^{3}$

According to the World Health Organization, dilated cardiomyopathy is characterized by inadequate dilation and contraction of the left ventricle or of both ventricles, ${ }^{4}$ 
and can be defined as idiopathic, familial or genetic, associated or not with an innate metabolic defect, viral and/or immunological, alcohol/toxin induced or associated with known cardiovascular diseases in which the degree of myocardial dysfunction cannot be explained by abnormal load conditions or by the extent of ischemic injury. Histology is non-specific. Presentation is normally by congestive heart failure, generally progressive. Arrhythmia, thromboembolism and sudden death are common and may occur at any stage of the disease. ${ }^{5-7}$

Within the pediatric group, IDCM is responsible for a large number of consultations and hospitalizations for HF not associated with congenital heart disease and, among under two-year-olds it is responsible for up to $29 \%$ of consultations. ${ }^{8}$ It results in a high mortality rate, with figures in published literature varying from $16 \%{ }^{9}$ at 10 years to rates as high as $49 \% 10,66 \%{ }^{11}$ and even $80 \%{ }^{12}$ at 5 years. For patients who progress badly with clinical treatment heart transplantation is the treatment of choice; global experience is currently exhibiting a survival curve of 75 to $80 \%$ at one year and 60 to $75 \%$ at 5.13-15

Malnutrition is a serious complication of chronic diseases including cancer, the acquired immunodeficiency syndrome and chronic heart failure. Since as long ago as the era of Hippocrates (460-370 BC), ${ }^{16}$ it has been known that weight loss, weakness and little resistance to physical exercise, accompanied by muscular atrophy, is part of the presentation of HF. Doubt persists in relation to the significance of malnutrition as a marker and predictor of death from IDCM in childhood.

With the intention of defining the significance of malnutrition as a predictor and marker for death in IDCM, the sample was analyzed in terms of epidemiological characteristics, weight percentile and standard deviation for weight (z score) as predictors of progress..

\section{Patients and methods}

A retrospective study based on the Instituto Nacional de Cardiologia database, from which the medical records of 165 patients were extracted consecutively for posterior analysis. The patients had been diagnosed with IDCM between September 1979 and March 2003, aged from day to 15.4 years. Inclusion criteria were the presence of $\mathrm{HF}$ associated with cardiomegaly in chest teleradiography and/or left ventricle (LV) dilation with reduced contractility observed by echocardiogram. Patients with a clinical diagnosis of myocarditis were not excluded from the study. Clinical criteria used to indicate myocarditis were: fever, chest pains, electrocardiogram (ECG) showing low QRS complex voltage or conductive or rhythmic anomalies or abnormal findings from laboratory tests for creatine phosphokinase (CK) and its myocardial fraction (CKmb). ${ }^{8}$ Patients were excluded if they had congenital heart disease, anomalous origin of the coronary arteries, Kawasaki disease, arrhythmogenic right ventricular cardiomyopathy, ischemic injury from neonatal asphyxia or after cardiorespiratory resuscitation, primary arrhythmias, congenital valve defects or defects caused by rheumatic disease, neuromuscular diseases, arterial hypertension, septicemia, HIV infection, Chagas' disease or diphtheria or if antineoplastic drugs had been used.

The variables analyzed were: sex, age and age group at onset (before 2 years vs. 2 years or older), previous history of viral illness during the 3 months preceding diagnosis and clinical myocarditis diagnosis. Patients were classified by functional class (FC) at onset according to the New York Heart Association (NYHA) criteria. These are: FC I - with no limitations to appropriate activity for age; FC II - comfortable at rest, but physical activity that is normal for age result in HF symptoms; FC III comfortable at rest, but physical activity results in symptoms of HF and FC IV - HF symptoms, even at rest, any physical activity increases discomfort. ${ }^{17}$

Weight and nutritional status assessment. Weight was measured 817 times during the follow-up period ( $x=4.95$ / patient); 744 weight measurements were taken during the first 72 months $(x=4.51 /$ patient). Initial weight was defined as that obtained before the end of the first month of progress, during which period 73 children were weighed 93 times ( $x=1.27 /$ patient). The relationship between number of weight measurements per patient and the duration of follow-up was: 3 months $=1.27 ; 6$ months $=1.61 ; 12$ months $=1.48 ; 18$ months $=1.56 ; 24$ months $=1.85 ; 36$ months $=1.52 ; 48$ months $=1.44 ; 60$ months $=1.33$ and 72 months $=1.57$. Weight percentiles and standard deviations for patient age and sex (z scores) were calculated using the EPINUT 2.0 anthropometry module of Epi-Info $6.04 \mathrm{c}$ by the CDC (Centers for Disease Control \& Prevention). The diagnostic criteria for malnutrition were either weight below the 2nd standard deviation (SD or $z<-2$ ) or the fifth percentile. Weight percentiles and $z$ scores were grouped at start (month zero) and at the 3rd, 6th, 12th, 18th, 24th, 36th 48th and 72nd months.

Classic pharmaceutical heart failure treatment was employed; consisting of oral digoxin, furosemide, sprinolactone, captopril and acetylsalicylic acid (ASA) for thromboembolic event prevention. The objectives of this study do not include any analysis of the influence of treatment on patient progress.

Statistical analysis was performed using Epi-Info 6.04 by the CDC (Centers for Disease Control \& Prevention) and Statistica 6.0 by Statsoft Inc. Dichotomous data was evaluated using the $\chi^{2}$ (chi-square) test and odds ratios (OR) were calculated when applicable with their $95 \%$ confidence intervals (CI95). Descriptive data was expressed as mean \pm standard deviation (SD) and value bands, and was analyzed with the Student t test. Continuous time-dependent variables were evaluated with analysis of variance (ANOVA) for unbalanced repeated measures and were grouped by outcome (survival vs. death) and by time since onset. Alpha was set as 0.05 and power at $80 \%$.

Ethical Factors: Authorization was obtained from the Commission for Ethics in Research at the Instituto Nacional de Cardiologia in Laranjeiras and the Universidade do Estado do Rio de Janeiro for information contained in medical record to be used in the study. 


\section{Results \\ General Characteristics}

Mean age at onset was $26.2 \pm 38.9$ months ( 0 to 188 months - median $=8.7$ months, $25 / 75 \%$ quartiles $=4.6$ and 22.8 ) or $2.1 \pm 3.2$ years ( 0 to 15.4 years - median $=0.71$ years, $25 / 75 \%$ quartiles $=0.39$ and 1.9 ). Mean follow-up time for the sample was $42.7 \pm 50.6$ (median $=24.4$ months, $25 / 75 \%$ quartiles $=7.3$ and 57.4 ) months or $3.55 \pm 4.21$ (median $=2.03$ years, $25 / 75 \%$ quartiles $=0.60$ and 4.78 ) years. At the end of the study $85(51.5 \%)$ patients continued under observation, $10(6.1 \%)$ had received medical discharges, $40(24.2 \%)$ had died and the hospital had lost contact with $30(18.2 \%)$, amongst which last the mean follow-up period had been 27.5 ( 0.1 to 94.9) months.

With respect of disease onset, there was an observed preference for the before two years old group (125 $75.8 \%$ - CI95 $=68.5 \%$ to $82.1 \% ; x=0.67 \pm 0.50$ years $)$ in comparison with the group of patients with onset after 2 years $(40-24.2 \%-\mathrm{CI} 95=17.9 \%$ to $31.5 \% ; \mathrm{x}=$ $6.77 \pm 3.63$ years $)(p<0.0001)$. There was no observed difference in terms of sex - females: $92(55.8 \%$ - CI95 = $47.8 \%$ to $63.5 \%)$ vs. males: $73(44.2 \%$ - CI95 $=36.5 \%$ to $52.2 \%)(p=0.14)$.

There were no differences in mortality between sexes ( $p$ $=0.88)$ or in terms of age group at diagnosis $(p=0.94)$. A majority of the patients $(103-62.4 \%-\mathrm{CI} 95=54.6 \%$ to $69.8 \%$ ) did not have viral disease prior to IDCM ( $p=$ 0.0018 ), although, when it was present, respiratory virosis was part of the primary condition $(53-85.5 \%-$ CI95 = $74.3 \%$ to $95.2 \%$ ), followed by gastrointestinal infection ( 9 $-14.5 \%$ - CI95 $=4.8 \%$ to $25.7 \%)(p<0.0001)$. There was no difference observed in mortality $(p=0.16)$ between the two groups. Previous viral disease was more common among those less than 2 years old $(51 / 62-82.3 \%-$ CI95 $=70.5 \%$ to $90.8 \%)(p<0.0001)(O R=21.50-$ CI95 $=7.86$ to 60.97$)$, with mean age of those with a viral condition being from $1.97 \pm 3.16$ years (median $=0,60$ years, $25 / 75 \%$ quartiles $=0.34$ and 1.68 ), for the whole sample and by age group $0.69 \pm 0.53$ years (median $=0.55$ years, $25 / 75 \%$ quartiles $=0.33$ and 0.93 ) for the under-two group and $7.92 \pm 3.48$ years (median $=6.07$ years, $25 / 75 \%$ quartiles $=4.04$ and 9.60) for those over two.

A clinical diagnosis of myocarditis was made at disease onset for 65 patients $(39.4 \%-$ CI95 $=31.9 \%$ to $47.3 \% p=$ $0.0001)$ and its presence did not affect mortality ( $p=0.35)$. The period since onset was not influenced by a diagnosis of myocarditis: myocarditis present $=39.37 \pm 45.86$ months $(0$ to 162 months - median $=23.2$ months, $25 / 75 \%$ quartiles $=5.1$ and 54.1) vs. myocarditis absent $=44.84 \pm 53.54$ months ( 0.23 to 241.5 months - median $=25.4$ months, $25 / 75 \%$ quartiles $=9.7$ and 58.8$)(p=0.4984)$. There was a strong association between myocarditis and previous viral disease $(p=0.0005)(O R=3.15-$ CI95 $=1.55$ to 6.44$)$. Accompanying fever not explained by associated infectious bacterial disease was present in $38.5 \%$ of the children with myocarditis $(p=0.0058)(O R=2.66-$ CI95 $=1.24$ to 5.74$)$.

The NYHA functional class criteria were used to evaluate initial clinical status severity. There were $13(7.9 \%)$ patients at FC I, $18(10.9 \%)$ at FC II, $36(21.8 \%)$ at FC III and $98(59.4 \%)$ at FC IV. The majority of the patients $(134-81.2 \%-$ CI95 $=74.4 \%$ to $86.9 \%)$ were, therefore, severe cases (FC III and IV) $(p<0.0001)$. All deaths occurred among patients classed as FC III/IV at first presentation $(p=0.0005)$.

\section{Weight and nutritional status}

Malnutrition was either present at presentation or occurred during clinical course in 84 of the patients in the sample studied $(50.9 \%-$ CI95 $=43.0 \%$ to $58.8 \%)$. At initial evaluation malnutrition was presented by $57 / 165$ (34.5\% CI95 $=27.3 \%$ to $42.3 \%)$, of whom $19 / 57$ died $(33.3 \%-$ CI95 $=21.4 \%$ to $47.1 \%)$. Death occurred in $21 / 98(21.4 \%$ - CI95 $=13.8 \%$ to $30.9 \%)(p=0.10)$ of those cases that had not presented malnutrition initially. Malnutrition occurred during the course of the disease in $27 / 98$ children $(27.5 \%$ - CI95 $=19 \%$ to $37.5 \%)$, who had not initially exhibited malnutrition, of whom $10(37 \%-$ CI95 $=19.4 \%$ to $57.6 \%)$ died. Eleven of the 71 cases that did not develop malnutrition resulted in death $(15.5 \%-$ CI95 $=8 \%$ to $26 \%)(p=0.02)$ $(\mathrm{OR}=3.21-\mathrm{CI95}=1.04$ to 9.95$)$.

There was no significant difference in terms of initial weight percentile between the survivors $(x=29.4 \pm 29.7)$ and those that died $(x=19.9 \pm 24.9)(p=0.15)$. The same was true of $z$ scores; survival $=-0.82 \pm 1.15 \mathrm{vs}$. death $=$ $-1.32 \pm 1.30(p=0.14)$

During the first 72 months the mean weight percentile for the whole sample was $29.4 \pm 31.8$ (0.0 to 99.8 - median $=15.5-25 / 75 \%$ quartiles $=2.9$ and 50.2 ), exhibiting a significant difference between the two outcome groups $(p<0.0001) ; 34.9 \pm 32.6$ for the survival group and $8.6 \pm 16.0$ for the death outcome group. The analysis of variance of the sample divided for outcome revealed a significant difference in the progress of weight percentiles between the two groups $(p=0.0417)$. Figure 1 shows the progress of weight percentiles for the two groups and their respective $95 \%$ confidence intervals.

During the first 72 months the mean z score for weight for the whole sample was $-0.91 \pm 1.48(-5.1$ to $6.16-$ median $=-1.01-25 / 75 \%$ quartiles $=-1.90$ and 0.01$)$, exhibiting a significant difference between the two outcome groups ( $p<0.0001$ ); $-0.62 \pm 1.43$ for survivors and $2.02 \pm 1.12$ for those that died. The analysis of variance of the sample divided for outcome revealed a significant difference in the progress of $z$ scores for weight between the two groups $(p=0.0005)$. Figure 2 shows the progress of $z$ scores for weight for the two groups and their respective $95 \%$ confidence intervals.

\section{Discussion}

Mean age at presentation was 2.1 years in this series ${ }^{18}$ which is similar to the majority of published reports, $10,11,19-21$ although some authors have found higher averages. $9,12,22,23$ In the sample studied here, disease onset exhibited a preference for the under two years age group $(75.8 \%)$, rather than the age $\geq 2$ years 


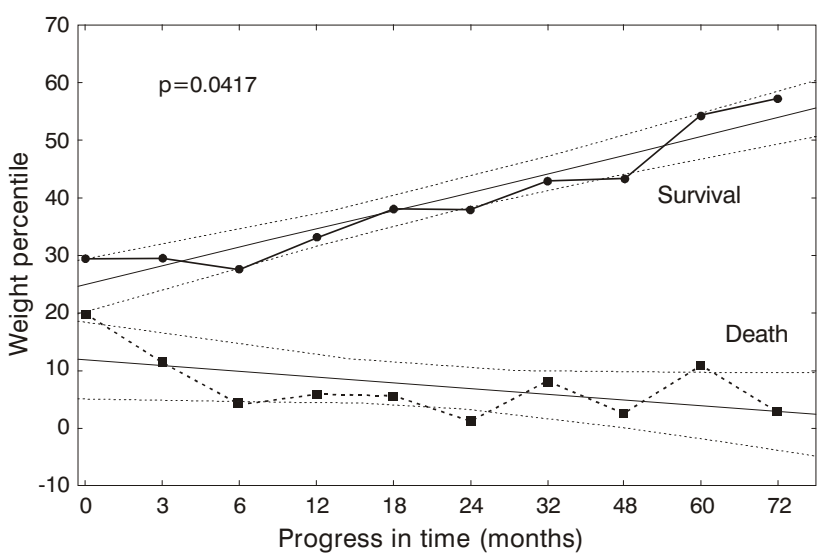

Figure 1 - Progress of weight percentiles for the two groups and their respective $95 \%$ confidence intervals

group. ${ }^{18}$ On this point there is no consensus in published literature, with some authors observing a similar situation 19,24 with others not doing so. 25,26

The age group at time of diagnosis did not affect mortality, ${ }^{18}$ which finding is identical to published observations, ${ }^{27-29}$ although Arola et al. ${ }^{10}$ found that, in a Finnish population, mortality was greater among those less than one year old with endocardial fibroelastosis and among male adolescents, while other authors have found elevated mortality among those older than two years. $19,24,30$

There was no observed difference in incidence according to sex, 18 which is in agreement with published data. $8-12,24,25,29,31,32$ Sex did not influence mortality in this series, 18 which is in agreement with other authors. $12,20,29$

Previous viral disease had been present in $37.6 \%$ of patients, 18 with viral infection rates in published literature being between $4.8 \%{ }^{19}$ and $54.2 \% .{ }^{11}$ Taliercio et al. ${ }^{11}$ relate lower mortality among a group that presented prior virosis, an observation that has not been repeated in other series. ${ }^{10,18}$

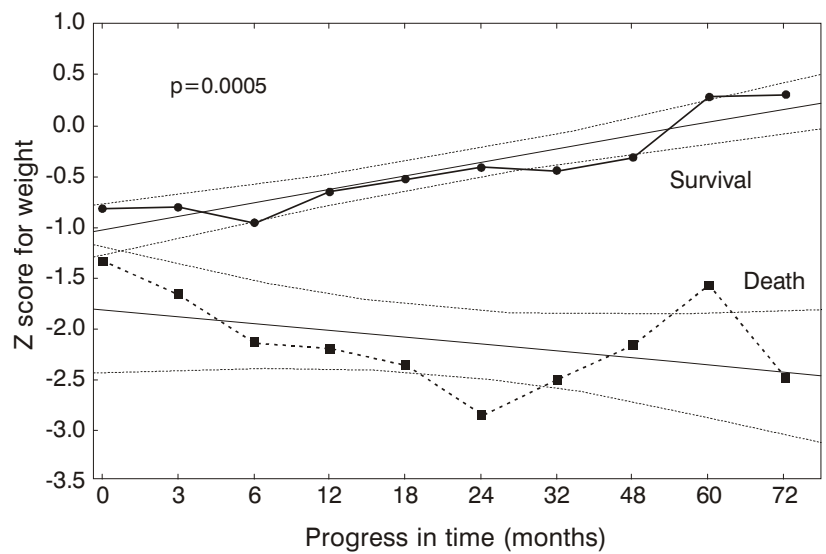

Figure 2 - Progress of $z$ scores for weight for the two groups and their respective $95 \%$ confidence intervals
Previous viral disease was more frequent among those under 2 years old. It could be speculated that this preference is due to this age group's greater susceptibility to viral respiratory disease, which had a mean onset age of $0.68 \pm 0.51$ year. It could be postulated that the differences in average age at IDCM onset to be found in published data could be related to differences in incidence and prevalence of viral diseases resulting in differences in the incidence and prevalence of myocarditis.

Patients with a clinical diagnosis of myocarditis were included in the study bearing in mind that the cause of dilated cardiomyopathy remains unknown even among patients with microscopic evidence of inflammation of the myocardium. 8,20,33-37 A clinical hypothesis of myocarditis was indicated in $39.4 \%$ of the patients in this series. ${ }^{18}$ No endomyocardial biopsies (EMB) were performed for myocarditis diagnosis because EMB involves certain risks, especially for infants; the sample may be removed from a health area; 8 a proportion of children with IDCM recover spontaneously and there is no specific treatment for myocarditis or IDCM currently available. ${ }^{10,34}$ Endomyocardial biopsies are being replaced with success by myocardial scintigraphy with gallium 67 , which offers a high level of correlation with EMB without the risks inherent in it. 34 Immunosuppressor treatment was not given to patients diagnosed with myocarditis, there is controversy in published literature over its efficacy. ${ }^{38-40}$

Silva et al. ${ }^{25}$ found clinical criteria for myocarditis in $47.4 \%$ of their sample, confirming this by means of EMB in three children more than 2 years old. In series in which EMB was performed, a diagnosis of myocarditis was established in between $19.5 \%$ and $72.7 \% .8,23,34,35,40$ In this series there was no observed difference in mortality, whereas, probably because of differences in myocarditis diagnostic criteria, some authors found improved prognosis among patients with EMB diagnosed myocarditis treated with immunosuppressive therapy. ${ }^{13}$ Strong associations were observed between clinical diagnosis of myocarditis, the presence of prior viral disease and age less than 2 years at onset. ${ }^{18}$

At the time of initial diagnosis, a majority (81.2\%) of cases were considered severe (FC III and IV) and all deaths occurred in this group of patients. In a Polish study there was no difference in severity distribution ( $p=$ 0.8274 ) and in a Brazilian one there was a predominance of less serious cases, i.e. FC I and II. 23,25 Ciszewski et al. ${ }^{23}$ did not find any differences in FC between the survival and death groups and Silva et al. ${ }^{25}$ did not describe the influence of FC on mortality.

Nutritional status assessment in HF patients, and in particular idiopathic dilated cardiomyopathy patients has been little investigated.

Saraiva et al. ${ }^{41}$ compared the hearts of 20 severely malnourished children with 10 healthy children paired for sex and age, observing disproportionately large left systolic e diastolic ventricles and atriums in relation to body surface area in the malnourished children; although with no significant difference in LV/body surface area due to relatively thin 
septal and posterior LV walls, and did not rule out the possibility that these findings were precursors of cardiomyopathy.

Cameron et al. ${ }^{42}$ assessed malnutrition in 160 children hospitalized with congenital heart disease for one year. They observed that acute malnutrition occurred in $33 \%$ and chronic in $64 \%$ of these children, although incidence, of both acute and chronic, increased to $70 \%$ for children with heart failure.

Anker et al., 43 studied 171 adult patients aged $60 \pm 11$ years and questioned the relationship between poor prognosis and wasting syndrome/cachexia. They compared ergometrically tested maximum $\mathrm{O}_{2}$ consumption $\left(\mathrm{VO}_{2}\right.$ $\max$ ) $(<14 \mathrm{vs} . \geq 14 \mathrm{ml} / \mathrm{kg} / \mathrm{min}$ ) with FC (NYHA), serum sodium and ejection fraction evaluated by nuclear medicine, in addition to assessing weight loss of more than $7.5 \%$ of pre-disease weight. Twenty-eight patients $(17.4 \%)$ were classed as having cachexia (loss of 9 to $36 \%-6 \pm 3.7 \mathrm{~kg}$ ), characterized as being older patients with lower capacity for exercise and low serum sodium. The Cox method demonstrated that all these were predictive factors for death; with an 18-month survival rate for those with cachexia of $50 \%$. When cachexia was associated with $\mathrm{VO}_{2}<14 \mathrm{ml} / \mathrm{kg} / \mathrm{min}$, the survival rate was $23 \%$, compared with $93 \%$ when neither factor was present. Fifty percent of those that died had cachexia.

Initial observed malnutrition was at $34.5 \%$ of the sample studied and malnutrition developed in $27.5 \%$ of patients. Malnutrition at onset did not affect death, but those children that developed malnutrition during the clinical course died in greater proportions with an OR of 3.21.44

When initial weight percentile and $z$ score for weight were analyzed no relationship was observed with death. The analysis of variance by death demonstrated significant differences between outcomes for: weight percentile $-p=$ 0.0417 and $z$ score for weight $-p=0.0005$. A progressive increase in weight percentiles and $z$ scores for weight was observed among surviving patients allowing patients who ought to survive to be separated at one month after diagnosis from those who run the risk of dying, using a $95 \%$ confidence interval

Mechanisms that could possibly cause malnutrition in IDCM are: malabsorption of nutrients because of intestinal edema; dietary deficiency and loss of nutrients via urinary and gastrointestinal losses. Digoxin provokes nausea in elevated doses and its levels should be carefully monitored in serum. It has been demonstrated in adults that a thiamin deficiency occurs with patients suffering from IDCM, possibly resulting from the use of loop diuretics (furosemide), since selenium and copper levels do not exhibit differences between groups. ${ }^{45}$ In the therapeutic follow-up of patients with IDCM, nutritional support with protein and vitamin supplementation is fundamental, especially thiamin since a deficiency worsens HF by mechanisms that are similar to what happens in beriberi.

Nutritional status evaluation is easily performed without any additional costs and can be done at the bedside in any location. We believe that nutritional assessments should be made a routine part of the follow-up of patients with chronic heart failure.

\section{References}

1. Talner NS. Heart failure. In: Moss AJ, Adams FH. Heart Disease in Infants, Children and Adolescents. 5th ed. Baltimore: Williams \& Wilkins; 1995. p. 1746-73.

2. Lewis $A B$. The failing myocardium. In: Chang $A C$, Hanley FL, Wernovsky G, Wessel DL. Pediatric Cardiac Intensive Care. 1st ed. Baltimore: Williams \& Wilkins; 1998. p. 483-96.

3. O'Laughlin MP. Congestive heart failure in children. Pediatr Clin North Am. 1999;46:263-73.

4. Richardson P. Report of the 1995 World Health Organization/ International Society and Federation of Cardiology Task Force on the Definition and Classification of Cardiomyopathies. Circulation. 1996;93:841-2.

5. Günthard J. Dilated cardiomyopathy in children and thromboembolism. Eur J Pediatr. 1997;156:3-6.

6. Chang YC. Left ventricular thrombi in children with dilated cardiomyopathy. J Formos Med Assoc. 1995;94:469-73.

7. Berger S. Sudden cardiac death in infants, children and adolescents. Pediatr Clin North Am. 1999;46:221-34.

8. Matitiau A, Perez-Atayde A, Sanders SP, Sluysmans T, Parness IA, Spevak PJ, et al. Infantile dilated cardiomyopathy - relation of outcome to left ventricular mechanics, hemodynamics, and histology at the time of presentation. Circulation. 1994;90: 1310-8.

9. Friedman RA, Moak JP, Garson A. Clinical course of idiopathic dilated cardiomyopathy in children. J Am Coll Cardiol. 1991;18: 152-6.

10. Arola A, Tuominen J, Ruuskanen O, Jokinen E. Idiopathic dilated cardiomyopathy in children: prognostic indicators and outcome. Pediatrics. 1998;101:369-76.

11. Taliercio CP, Seward JB, Driscoll DJ, Fisher LD, Gersh BJ, Tajik AJ. Idiopathic dilated cardiomyopathy in the young: clinical profile and natural history. J Am Coll Cardiol. 1985;6:1126-31.

12. Akagi T, Benson LN, Lightfoot N, Chin K, Wilson G, Freedom RM. Natural history of dilated cardiomyopathy in children. Am Heart J. $1991 ; 121: 1502-6$.

13. Wong PC, Starnes VA. Pediatric heart and lung transplantation. In: Chang AC, Hanley FL, Wernovsky G, Wessel DL. Pediatric Cardiac Intensive Care. 1st ed. Baltimore: Williams \& Wilkins; 1998. p. 327-43.

14. Canter CE. Current outcomes in pediatric thoracic transplantation. ACC Cur J Rev. 1999;6:65-8.

15. Azeka E, Barbero-Marcial M, Jatene M, Camargo PR, Auler JOC, Atik $E$, et al. Transplante cardíaco no neonato e na infância. Resultados a médio prazo. Arq Bras Cardiol. 2000;74:197-202.

16. Katz AM, Katz PB. Diseases of heart in works of Hippocrates. $\mathrm{Br}$ Heart J. $1962 ; 24: 257-64$

17. The Criteria Committee of the New York Heart Association: Nomenclature and Criteria for Diagnosis. 9th ed. Boston: Little Brown; 1994.

18. Azevedo VMP, Santos MA, Albanesi Filho FM. Características epidemiológicas da cardiomiopatia dilatada idiopática na infância. Rev SOCERJ. 2000;13 (Supl A):56.

19. Burch M, Siddiqi SA, Celermajer DS, Scott C, Bull C, Deanfield JE. Dilated cardiomyopathy in children: determinants of outcome. Br Heart J. 1994; 72:246-50.

20. Torres F, Anguita M, Gimenez TD, Franco M, Zayas R, Gallardo $A$, et al. Miocarditis aguda con disfunción cardíaca severa en la población pediátrica. Evolución y características diferenciales con respecto a la miocarditis del adulto. Rev Esp Cardiol. 1995;48:660-5.

21. Müller G, Ulmer HE, Hagel KJ, Wolf D. Cardiac dysrhythmias in children with idiopathic dilated or hypertrophic cardiomyopathy. Pediatr Cardiol. 1995;16:56-60.

22. Lewis AB. Prognostic value of echocardiography in children with idiopathic dilated cardiomyopathy. Am Heart J. 1994;128:133-6.

23. Ciszewski A, Bilinska ZT, Lubiszewska B, Ksiezycka E, Poplawska W, Michalak E, et al. Dilated cardiomyopathy in children: clinical course and prognosis. Pediatr Cardiol. 1994;15:121-6.

24. Griffin ML, Hernandez A, Martin TC, Goldring D, Bolman M, Spray $\mathrm{TL}$, et al. Dilated cardiomyopathy in infants and children. J Am Coll Cardiol. 1988;11:139-44. 
25. Silva MAD, Silva RP, Morais SC, Fragata Filho AA, Correia EB. Aspectos clínicos e evolutivos da miocardiopatia dilatada nos lactentes e na infância. Arq Bras Cardiol. 1991;56:213-18.

26. Lewis $A B$. Late recovery of ventricular function in children with idiopathic dilated cardiomyopathy. Am Heart J. 1999;138:334-8.

27. Chen SC, Nouri S, Balfour I, Appleton RS. Clinical profile of congestive cardiomyopathy in children. J Am Coll Cardiol. 1990;15:189-93.

28. Lewis AB. Outcome of infants and children with dilated cardiomyopathy. Am J Cardiol. 1991;68:365-9.

29. Nogueira G. Miocardiopatia dilatada idiopática na criança: perfil clínico e determinantes do prognóstico. Rev Port Cardiol. 2000;19:191-200.

30. Di Filippo S. Les myocardiopathies dilatees idiopathiques de I'enfant. Evolution et facteurs pronostiques. Arch Mal Coeur Vaiss. 1991;84:721-6.

31. Venugopalan $P$. Improved prognosis of heart failure due to idiopathic dilated cardiomyopathy in children. Int J Cardiol. 1998;65:125-8.

32. Cabrera A. Dilated myocardiopathy in children. Rev Esp Cardiol. 1990;43:246-50.

33. Herdy GVH, Menezes DMF, Lopes VGS, Azevedo SM, Odeh CSA, Mendonça $C$, et al. Miocardite por citomegalovírus em lactentes. Arq Bras Cardiol. 1988;50:397-400.

34. Camargo PR, Mazzieri R, Snitcowsky R, Meneguetti C, Soares Jr J, Higuchi $M L$, et al. Biópsia endomiocárdica e mapeamento miocárdico com gálio-67 no diagnóstico de miocardite ativa em crianças portadoras de miocardiopatia dilatada. Arq Bras Cardiol. $1990 ; 54(1): 27-31$.

35. Webber SA, Boyle GJ, Jaffe R, Pickering RM, Beerman LB, Fricker FJ. Role of right ventricular endomyocardial biopsy in infants and children with suspected or possible myocarditis. Br Heart J. $1994 ; 72: 360-3$.

36. Lee KJ. Clinical outcomes of acute myocarditis in childhood. Heart. 1999;82:226-33.

37. Rezkalla SH, Raikar S, Kloner RA. Treatment of viral myocarditis with focus on captopril. Am J Cardiol. 1996;77:634-7.
38. Higuchi ML. Resposta histológica do miocárdio a diferentes esquemas imunossupressores em pacientes com cardiomiopatia dilatada e diagnóstico de miocardite à biópsia endomiocárdica. Arq Bras Cardiol. 1990;54:319-22.

39. Camargo PR. Drogas imunossupressoras no tratamento da miocardite ativa na criança. avaliação hemodinâmica. Arq Bras Cardiol. 1990;55:295-9.

40. Kleinert S. Myocarditis in children with dilated cardiomyopathy: incidence and outcome after dual therapy immunosuppression. J Heart Lung Transplant. 1997;16:1248-54.

41. Saraiva LR, Brindeiro Filho D, Nora AD. O coração na criança portadora de desnutrição calórico-protéica severa. Arq Bras Cardiol. 1992;58:353-7.

42. Cameron JW, Rosenthal A, Olson AD. Malnutrition in hospitalized children with congenital heart disease. Arch Pediatr Adolesc Med. 1995;149:1098-102.

43. Anker SD. Cachexia in heart failure is bad for you. Eur Heart J. 1998; 19:191-3.

44. Azevedo VMP, Santos MA, Albanesi Filho FM. O valor do percentil de peso e da desnutrição como fatores prognósticos na cardiomiopatia dilatada idiopática da infância. Rev SOCERJ. 2000;13 (Supl A):56.

45. da Cunha S, Albanesi Filho FM, da Cunha Bastos VL. Thiamin, selenium, and copper levels in patients with idiopathic dilated cardiomyopathy taking diuretics. Arq Bras Cardiol. 2002;79: 454-65.

Corresponding author:

Vitor Manuel Pereira Azevedo

Rua Visconde de Ouro Preto, 39/304

CEP 22250-180 - Rio de Janeiro, RJ, Brazil

Tel.: + 55 (21) 2552.4123/9966.4708

E-mail: vitoraze@cardiol.br 